\title{
Hamster Small Intestinal Neoplasm
}

National Cancer Institute

\section{Source}

National Cancer Institute. Hamster Small Intestinal Neoplasm. NCI Thesaurus. Code C134994.

A neoplasm that occurs in the small intestine of a hamster. 